\title{
Multiple Intelligences in Change Leadership: Exploring the Diversity
}

\author{
Jennifer Palthe ${ }^{1, *}$ \\ ${ }^{1}$ Department of Management, Western Michigan University, Kalamazoo, USA \\ *Correspondence: Department of Management, Haworth College of Business, Western Michigan University, 1903 \\ W Michigan Ave, Kalamazoo, MI 49008-5429, USA. Tel: 1-269-387-5798. E-mail: jennifer.palthe@wmich.edu
}

Received: January 16, 2019 Accepted: February 13, 2019 Online Published: February 18, 2019

doi:10.5430/mos.v6n1p1

URL: https://doi.org/10.5430/mos.v6n1p1

\begin{abstract}
This paper explores the role of emotional intelligence, executive intelligence, and cultural intelligence necessary for effective change leadership. With dramatic advancements in technology and global interconnectivity, and growing demands for more culturally aware and emotionally resilient change leaders, the use and development of multiple intelligences is shown to be vital for successful change. The key distinctions and connections between these intelligences and their relationship to change leadership are examined, and implications for future research and practice are extended.
\end{abstract}

Keywords: change leadership, emotional intelligence, executive intelligence, cultural intelligence

\section{Introduction}

Well into the 1980s, leadership development was largely a process of promoting more data-driven individuals with high general intelligence quotients derived from standardized tests (Hunter \& Hunter, 1984; Hunter \& Schmidt, 1990). However, today, employers are seeking leaders who are not just intellectually astute from a general intelligence standpoint, but who possess strong emotional intelligence (Salovey \& Mayer, 1990; Goleman, 2004), executive intelligence (Menkes, 2005), and cultural intelligence (Early \& Mosakowski, 2004; Van Dyne \& Kim, 2012). The past decade has seen a substantial increase of research in these areas, but little has been done to integrate them to inform researchers, educators, and practitioners.

With dramatic developments in technology and global interconnectivity, and the complexity of change in organizations and society, extraordinary change leadership has become essential. Where simply being effective at managing the change of existing organizational methods and systems was once sufficient, there is now a demand for more global, inclusive, culturally aware, emotionally resilient and resonant change leadership (Goleman, Boyatzis, \& McKee, 2013). The call and need of this new era are for passionate fulfillment (Collins, 2001), finding your voice, and inspiring others to do likewise (Covey, 2004). Finding this voice and employing the higher reaches of human genius and motivation requires a new set of change leadership competencies that tap into multiple intelligences. Moreover, we are also observing growing research evidence for the importance of leadership benevolence and compassion, and the value of leader contributions to the greater community (Bolman \& Deal, 2011; Boyatzis \& McKee, 2005).

It is well recognized that the development of change leadership significantly improves the successful implementation of organizational change (Gao-Urhahn, Biemann \& Jaros, 2016; Ling, Guo, \& Chen, 2018). Change leadership theory and research indicates this success is also attributable to the ability of change leaders to facilitate and engage change constituents (Higgs \& Rowland, 2011). These approaches are associated with research streams addressing emotional, executive and cultural intelligence, but there remains a paucity of research that integrates these concepts.

A recent market trend survey sponsored by the Association to Advance Collegiate Schools of Business (AACSB), the Executive MBA Council, and the Executive Education Consortium pointed to the growing requirements of leaders to be able to address more complex challenges in a more unpredictable global business environment. The study also noted that the educational community has been slow to adjust to these developments (Lubeck, Cheng, Myszkowski, Doedijns, Drew, \& Snow, 2015). Additionally, with research evidence indicating failed change 
initiatives and unsuccessful change leadership in volatile business environments (Beer, 2000; Pettigrew, Woodman, \& Cameron, 2001), it's apparent that general intelligence and traditional change leadership models alone are insufficient to prepare for and implement sustainable change. Likewise, Menkes (2005) asserts that traditional intelligence tests fail to assess the practical, on-your-feet thinking skills needed in organizations, and the skills that these tests assess represent only a fraction of what makes leaders effective. Similarly, Goleman (2005) insists that only roughly ten percent of effectiveness in leadership is attributable to cognitive abilities. These challenges may provide additional explanatory reasons for why so many organizational change initiatives fail. Could it be that the change leaders lack the necessary emotional intelligence to appreciate the emotions of change recipients during the change? Is it possible that change leaders fail to overcome change resistance because they lack the necessary cultural intelligence to empathize with diverse change constituents and gain their commitment to long-term change? Could it be that change leaders understand change theory but fail to exercise executive intelligence due to poor judgment and lack of careful forethought?

This paper seeks to provide an overview of these intelligences - emotional, executive and cultural - in relation to change leadership. The interplay between these various intelligences and their relationship to change leadership is explored, and implications for research and practice are extended.

\section{Emotional, Executive, and Cultural Intelligence}

While the study of intelligence has historically focused on the adaptive use of cognition (Piaget, 1972), the eighties began to produce more encompassing approaches to understanding the concept. Gardner (1983) developed the theory of multiple intelligences that dealt with interpersonal, intrapersonal, linguistic, logical, naturalist, visual-spatial, musical and bodily-kinesthetic intelligence as distinct from general intelligence or academic intelligence quotient (IQ). Gardner's (1983) theory of multiple intelligences emphasized intrapersonal and interpersonal intelligences that involve the capacity to relate to others successfully in the practicalities of life that are distinct from IQ. The concept of emotional intelligence is grounded in Gardner's (1983) work, that suggests that human intelligence is multidimensional. Salovey and Mayer (1990) introduced the concept of emotional intelligence defining it as the capacity to monitor one's feelings and the feelings of others, to distinguish among them, and the ability to use this information to guide one's behavior. Emotional intelligence essentially is comprised of three adaptive abilities: appraisal and expression of emotion, regulation of emotion, and utilization of emotions in solving problems (Salovey \& Mayer, 1990). In 1993 Gardner further developed his 1983 theory of multiple intelligences, and Goleman (1995) made popular the notion of viewing the expression of emotions as a domain of intelligence. Goleman (1995) expanded Salovey and Mayer's (1990) conceptualization of emotional intelligence to five domains: self-awareness of emotions, self-regulation of emotions, motivation, empathy, and relationship management. Goleman (1995) views leadership as the art of persuading people to work toward a common objective through primarily emotional competencies. From this standpoint, IQ alone would not be sufficient to explain and ensure success in leading change. Emotional intelligence would be considered a more significant explanatory variable. Transformational leadership theories concur with this view and suggest that tomorrow's leaders must emotionally engage followers to perform beyond organizational expectations (Bass \& Avolio, 1994). Moreover, Gardner and Avolio (2005) emphasize the importance of leader emotions and their relationship to authentic leadership. Authentic leaders possess a deep awareness of how they think and behave and how they are perceived by others with respect to values and moral perspectives, the context in which they operate, confidence, hopefulness, resilience, and high moral character (Avolio, Gardner, Walumba, Luthans, \& May, 2004).

Focusing on the role of emotional intelligence in change leadership effectiveness, without also giving consideration to the critical thinking processes involved in change leadership is potentially inadequate. We therefore need to consider the concept of executive intelligence, introduced by Menkes (2005). Executive intelligence involves a distinct set of aptitudes that predicate success in the accomplishment of tasks, working with and through other people, and personal judgment and behavioral adaptation. Critical thinking is the foundation of executive intelligence. It is the type of intelligence associated with all facets of management and forms the basis of smart executive behavior. Those who possess high executive intelligence will critically examine the accuracy and underlying assumptions of a given business scenario and will articulate the strengths and weaknesses of the suggestions posed by others. Exhibitors of high executive intelligence will also appropriately consider the probable effects and likely unintended consequences of not taking a particular course of action. All of these attributes are highly relevant and useful for effective change leadership. Intelligent executives tend to make decisions using multiple perspectives to identify probable unintended consequences of various action plans (Menkes, 2011). While empirical research testing 
executive intelligence is limited, it still presents another valuable form of intelligence that is worthy of further exploration since it captures aspects of real-time managerial performance that other methodologies do not.

While exploring change leader critical thinking strategies and emotions is important, there is potential for cultural differences in the thinking processes as well as the perception and management of emotions (Van Rooy \& Viswesvaran, 2004). We therefore need to consider the notion of cultural intelligence. Earley and Ang (2003) introduced the concept of cultural intelligence, defining it as the capacity to function effectively in culturally diverse settings. It involves the ability to swiftly switch cultural contexts with the appropriate behavioral responses. This behavioral flexibility allows leaders with high cultural intelligence to enhance the performance of multicultural teams and enact appropriate verbal and non-verbal behaviors to fit specific cultural contexts (Shokef \& Erez, 2008). Ang and Van Dyne (2008) conceptualized cultural intelligence as a four-factor construct that includes metacognitive, cognitive, motivational, and behavioral dimensions. Van Dyne, Ang, Ng, Rockstuhl, Tan, and Koh (2012) subsequently developed eleven sub-dimensions of each of the four-factor model. Since then, research on cultural intelligence has developed significantly together with the theoretical and practical utility of the concept (Rockstuhl \& Van Dyne, 2018). Cultural intelligence displays abilities that are specifically relevant to situations involving cultural diversity (Van Dyne, \& Kim, 2012) and leaders with high cultural intelligence act appropriately and effectively in new cultural environments, not because of tacit knowledge or emotional intelligence, but due to an understanding and mastery of cultural situations (Earley \& Mosakowski, 2004). Empirical research has also shown that cultural intelligence is negatively associated with burnout among leaders working in multinational companies (Tay, Westman \& Chia, 2008). In organizational change contexts, where organizations are either expanding their global reach or transforming their organizational culture, cultural intelligence becomes particularly helpful in ameliorating the challenges associated with cross-cultural adjustment and burnout. Change leaders that possess high cultural intelligence are likely to be more effective at handling cross-cultural adjustments, as well as generating support for and sustaining organization culture change. Leaders with high cultural intelligence will also be able to interpret novel cultural interactions, understand the similarities and differences across cultures, be more persistent in stressful settings, and be more socially adept in dealing with complex cultural changes (Van Dyne \& Kim, 2012).

\section{Multiple Intelligences and their Relationship to Change Leadership Theory}

The predominant approach to leadership studies over the past few decades has been quantitative (Avolio, Walumba, $\&$ Weber, 2009) and few studies have examined the change leader's role in the organizational change process. One of the few exceptions is the research by Higgs and Rowland (2000, 2005, 2011). Higgs and Rowland (2000) identified five key change leadership competencies necessary for implementing change. These critical change leadership competencies all have connections with multiple types of intelligences (executive, emotional, and cultural). In order for a change leader to effectively engage others in recognizing the need for change (Higgs and Rowland's first change leadership competency), they would need to possess effective social skills, empathy, cultural flexibility, and self-awareness, all of which are associated with emotional and cultural intelligence. For change leaders to ensure that the change is based on a thorough understanding of the issues and supported by a consistent set of tools and processes (Higgs and Rowland's second leadership competency), they would need to have strong executive intelligence to carefully and accurately assess the current status quo and begin to find solutions and make complex decisions that employ effective judgment. In order for change leaders to effectively engage others in the whole process and build commitment (Higgs and Rowland's third leadership competency) they would need to have strong emotional and cultural intelligence to address the feelings and values of the change recipients in a way that strengthened their commitment to the change. If the change recipients feel they have been excluded in what otherwise may have been a successful initiative, the entire change process may be undermined and resisted. For change leaders to effectively implement and sustain change (Higgs and Rowland's fourth change leadership competency) they would need to foster sound critical thinking and accurate analyses of the change outcomes, maintain positive emotions towards the change, sustain shared values, and preserve consistent beliefs about the change amongst all the stakeholders. Emotional, executive and cultural intelligence are all clearly at play. If change leaders lacked cultural intelligence, for example, sustaining the change, even if it was implemented successfully, would be undermined. For change leaders to effectively ensure that people are challenged to find their own answers and are supported in that (Higgs and Rowland's fifth change leadership competency), they would need to have strong social skills, empathy, and self-regulation skills, all of which are closely associated with emotional and cultural intelligence.

Using Higgs and Rowland's (2005) three broad leadership behavioral sets and their impact on change success in 
differing contexts, the connections with executive, emotional and cultural intelligence again become apparent. The first broad category offered by Higgs and Rowland (2005) is "shaping behavior." This change leadership behavior involves things like thinking about the change (relevant to executive intelligence). Their second behavioral category is "framing change," involving designing and establishing an emotional connection to the change and communicating its guiding principles (relevant to emotional intelligence). Their third and final category is "creating capacity," that involves creating capabilities and communication, and making connections, which applies to both cultural and emotional intelligence. Higg's and Rowland's (2005) research findings suggested that the "shaping" behaviors on the part of the change leaders had an adverse impact on the change success in all the contexts they explored. Since "shaping" was associated mainly with getting people to think about the change, it is therefore more closely linked to executive intelligence capabilities. This may suggest that executive intelligence alone may be helpful to initially identify and analyze the need for change but without emotional and cultural intelligence, the change is unlikely to be optimally adopted and sustained. Higgs and Rowland's (2005) findings also suggested that "framing" and "creating" change leadership behaviors were strongly linked to the recognition that change involves complexity and uncertainty across multiple contexts. The leader's cultural intelligence would therefore play a significant role in ameliorating these challenges.

Higgs and Rowland's (2011) research identifies four key change leader behaviors namely "attractor," "edge and tension," "container," and "transforming space." "Attractor" behavior creates a dynamic force in an organization to propel it to its purpose. "Edge and tension" entail the change leader's testing and challenging an organization to highlight unhelpful patterns in the change process. This is closely aligned with executive intelligence that involves critical thinking and evaluative processes to ensure optimal leadership behavior. "Container" leader behavior provides stability and affirmation in the face of uncertainty. This is closely associated with emotional and cultural intelligence where adaptability to new contexts and social skills become paramount. "Transforming space" leader behavior entails focusing on allowing oneself to be vulnerable and displaying empathy and care in change process. This has links to emotional and cultural intelligence since they both include dimensions associated with empathy.

Table 1 below further clarifies some of the key dimensions along which these intelligences differ. As portrayed, each of these intelligences, provides a basis for predicting change leadership behavior. Executive intelligence emphasizes critical thinking, working with and through others, and task accomplishment. Emotional intelligence stresses self-awareness and self-regulation of feelings, motivation, empathy, and social skills in promoting and sustaining change. Cultural intelligence emphasizes values and norms linked to cognitive, physical, and motivational components of change. Higgs and Rowland's (2005) change leader behavior sets (shaping, framing, and creating) are associated with each type of intelligence. Executive intelligence, since it deals with thinking processes, is more closely aligned with the change leader behavior of "shaping." Emotional intelligence relates more closely to the change leader behavior set of "framing and creating" since it involves communicating and connecting emotionally. Cultural intelligence relates more closely to the change leader behavior set of "framing and creating" since it involves communicating and connecting cross-culturally. As reflected under the row on change leader competencies, change leaders with high executive intelligence will be competent at ensuring that the change is supported by a consistent set of tools and processes. Change leaders with high emotional intelligence will be competent at effectively engaging others emotionally and change leaders with high cultural intelligence will be competent at engaging others well cross-culturally. Table 1 also highlights key change leadership skills associated with each intelligence. Change leaders with strong executive intelligence will appropriately define change problems and be skilled at distinguishing the essential change objectives from the less-relevant ones. Such leaders will be skilled at anticipating obstacles to change, will critically examine assumptions associated with the need to change, and will appropriately consider the probable outcomes of the change. Change leaders with strong emotional intelligence will be strongly aware of how their own emotions affect others while leading change. These leaders will be skilled at regulating their own emotions, promoting diversity, and fostering effective interpersonal skills throughout the change process. Change leaders with strong cultural intelligence will be skilled at quickly and appropriately adapting to new cultural contexts. Such leaders will display confidence and empathy when dealing with employees and customers from different cultures and will possess the skills to engender more effective organizational culture change. 
Table 1. Multiple Intelligences in Change Leadership

\begin{tabular}{|c|c|c|c|}
\hline & $\begin{array}{l}\text { Executive } \\
\text { Intelligence }\end{array}$ & $\begin{array}{l}\text { Emotional } \\
\text { Intelligence }\end{array}$ & $\begin{array}{l}\text { Cultural } \\
\text { Intelligence }\end{array}$ \\
\hline Leading Scholars & Menkes $(2005,2011)$ & $\begin{array}{l}\text { Salovey and Mayer, } \\
(1990) \\
\text { Goleman }(1995,2004)\end{array}$ & $\begin{array}{l}\text { Earley and Ang (2003) } \\
\text { Earley and Mosakowski } \\
(2004) \\
\text { Ang and Van Dyne } \\
(2008)\end{array}$ \\
\hline $\begin{array}{l}\text { Core Constructs } \\
\text { Key Dimensions }\end{array}$ & $\begin{array}{l}\text { Thoughts } \\
\text { Critical thinking } \\
\text { Accomplishing tasks } \\
\text { Working with \& } \\
\text { through others }\end{array}$ & $\begin{array}{l}\text { Feelings and emotions } \\
\text { Self-awareness } \\
\text { (perception \& } \\
\text { knowledge of } \\
\text { emotions) } \\
\text { Self-regulation } \\
\text { (management of } \\
\text { emotions) } \\
\text { Motivation } \\
\text { Empathy } \\
\text { Social skills } \\
\text { (integration \& } \\
\text { assimilation of } \\
\text { emotions) }\end{array}$ & $\begin{array}{l}\text { Values and norms } \\
\text { Cognitive Cultural } \\
\text { Quotient (CQ) } \\
\text { Physical CQ } \\
\text { Emotional/ Motivational } \\
\text { CQ } \\
\text { Behavioral CQ }\end{array}$ \\
\hline $\begin{array}{l}\text { Change Leader } \\
\text { Behavior Sets } \\
\text { (Higgs and Rowland, } \\
2005 \text { ) }\end{array}$ & $\begin{array}{l}\text { Shaping } \\
\text { (thinking about the } \\
\text { change) }\end{array}$ & $\begin{array}{l}\text { Framing and creating } \\
\text { capability } \\
\text { (communicating \& } \\
\text { connecting } \\
\text { emotionally) }\end{array}$ & $\begin{array}{l}\text { Framing and creating } \\
\text { capability } \\
\text { (communicating \& } \\
\text { connecting } \\
\text { cross-culturally) }\end{array}$ \\
\hline \multirow[t]{2}{*}{$\begin{array}{l}\text { Change Leader } \\
\text { Competencies } \\
\text { (Higgs and Rowland, } \\
\text { 2000) }\end{array}$} & $\begin{array}{l}\text { Ensure that the change } \\
\text { is supported by a } \\
\text { consistent set of tools } \\
\text { and processes }\end{array}$ & $\begin{array}{l}\text { Effectively engage } \\
\text { others emotionally to } \\
\text { build commitment }\end{array}$ & $\begin{array}{l}\text { Effectively engage } \\
\text { others cross-culturally to } \\
\text { build commitment }\end{array}$ \\
\hline & & $\begin{array}{l}\text { Effectively implement } \\
\& \text { sustain change }\end{array}$ & $\begin{array}{l}\text { Effectively implement } \\
\text { and sustain change }\end{array}$ \\
\hline $\begin{array}{l}\text { Change Leader } \\
\text { Skills }\end{array}$ & $\begin{array}{l}\text { - Appropriately } \\
\text { defines change } \\
\text { problems \& } \\
\text { differentiates essential } \\
\text { change objectives } \\
\text { from less-relevant } \\
\text { concerns } \\
\text { - Anticipates obstacles } \\
\text { to change } \\
\text { - Critically examines } \\
\text { assumptions } \\
\text { associated with the } \\
\text { need to change } \\
\text { - Articulates strengths } \\
\text { of suggestions for } \\
\text { change } \\
\text { - Considers probable } \\
\text { effects of change } \\
\text { - Uses multiple } \\
\text { perspectives }\end{array}$ & $\begin{array}{l}\text {-Strongly aware of } \\
\text { how own emotions } \\
\text { affect others while } \\
\text { leading change } \\
\text { - Controls emotions \& } \\
\text { withholds judgment } \\
\text { even when changes } \\
\text { become challenging } \\
\text { - Promotes feelings of } \\
\text { inclusion in the change } \\
\text { process } \\
\text { - Enhances workplace } \\
\text { diversity } \\
\text {-Intrinsically motivated } \\
\text { - Fosters effective } \\
\text { interpersonal skills } \\
\text { throughout the change } \\
\text { process }\end{array}$ & $\begin{array}{l}\text { - Switches cultural } \\
\text { contexts quickly \& acts } \\
\text { appropriately (in } \\
\text { organizational and/or } \\
\text { international culture } \\
\text { contexts) } \\
\text {-Confident in dealing } \\
\text { with employees \& } \\
\text { customers from different } \\
\text { cultures } \\
\text {-Demonstrates empathy } \\
\text { towards people from } \\
\text { different cultures } \\
\text { - Easily adapts to } \\
\text { another culture } \\
\text { (organizational and/or } \\
\text { international) }\end{array}$ \\
\hline
\end{tabular}




\section{Multiple Intelligences, Change Drivers, Resistance, and Change Sustainers}

By relating the various types of intelligences to organizational change further, the factors that potentially play a role in providing the drivers of change, change resistance, and the capacity to sustain change are illuminated.

From the executive intelligence perspective, critical thinking and task accomplishment may be the essential drivers of organizational change, with the ability to use multiple perspectives and the anticipation of obstacles serving as the key factors sustaining that change. Here, members initiate and support a change through a critical thinking and problem-solving process. Leaders with high executive intelligence in change scenarios will be able to analyze, communicate the rationale behind the change, offer logical reasoning for why the change is needed, and assess the tasks that need to be accomplished for the change to be successful. Practitioners emphasizing executive intelligence in driving organizational change are likely to view positive organizational change as fundamentally a product of sound executive judgment, effective critical thinking and accurate analytical processes. They are also more likely to emphasize the immediate environment and tasks than the broader cultural context of the organization in driving or constraining an organizational change. The chief role of change leaders with high executive intelligence will be to generate efficient task-related solutions to complex change challenges through disciplined and accurate analytic processes.

From the emotional intelligence perspective, self-awareness, motivation, and empathy may be the key drivers of organizational change, with the ability for self-regulation and social skills serving as the main factors that perpetuate the change. Here, members choose to adopt and support a change because they feel strongly about the need for the change, they also empathize strongly with the change recipients, and feel emotionally connected to the outcomes of the change. Leaders with high emotional intelligence in change scenarios will display strong self-awareness and self-regulation of behaviors prior to, during the transition, and post-change. They will provide meaning and inspire change recipients to adopt the change. They will also display emotional confidence, optimism and enthusiasm for the change, despite setbacks. Change leaders with high emotional intelligence will be able to arouse team spirit and group synergy, helping the change recipients to forge a bond of unity during the change process. They will guide the change initiative through to completion, maintaining personal self-composure and self-control. They will also have the capacity to recognize the effect of their behavior on others, and lead with discretion and empathy towards all the stakeholders associated with the change. Practitioners emphasizing emotional intelligence, are likely to stress the role of monitoring the feelings of the change agents and the change recipients. They will emphasize the importance of having a sense of how organizational members feel about change decisions, why they were made, and what the outcomes of the change will generate. They are also more likely to empathize with the change resistors and their needs, and to generate alignment between the diverse interests of all the change recipients.

From the cultural intelligence perspective, confidence in dealing with employees and customers from diverse cultures may be an essential driver of organizational change, with the change leader's ability to demonstrate empathy towards people from other cultures serving as the key factor that sustains that change. Here, change recipients may choose to adopt and support a change because they value the purpose and outcomes of that change, and because their personal norms align with the new proposed norms. Leaders with high cultural intelligence in change scenarios will display clear appreciation for values associated with multiple cultures, and will display empathy prior to, during the transition, and post-change. They will demonstrate a capacity to swiftly switch cultural contexts, with the culturally appropriate behavioral responses that minimize change resistance and promote enduring change. Practitioners emphasizing cultural intelligence will emphasize the role of shared values and norms in the cultural context and how these may drive or inhibit the successful implementation of change. This perspective will also stress the importance of achieving change that is internalized by organizational members and culturally supported.

\section{Implications for Practice}

Training and development of change leaders would benefit from a more explicit emphasis on emotional, executive, and cultural intelligence. All these intelligences are malleable capabilities and can therefore be enhanced through training and development activities. Since the ability to manage in contexts characterized by cultural diversity is a precondition to effective international leadership (Manning, 2003), cultural intelligence should predict international change leadership success. Similarly, emotional intelligence, with its strong emphasis on social skills and empathy in diverse contexts, should enhance change leadership effectiveness when an organization is undergoing significant culture change. Also, since change leaders that develop in cultural intelligence are likely to interpret novel cultural interactions better, creating training and development experiences that foster cultural intelligence would be beneficial in the case of mergers and acquisitions of organizations with diverse organizational cultures and national cultures. 
Executive, emotional and cultural intelligence also offer key selection criteria useful in recruiting, promoting and rewarding change leaders. More attention could be given to rewarding change leaders who anticipate obstacles to the change and critically examine assumptions associated with the change diagnostics (executive intelligence), who can function well in multicultural groups (cultural intelligence), and who have strong self-awareness, self-regulation, and social skills (emotional intelligence). With change leadership significantly improving the successful implementation of organizational change, developing these vital capacities should be a top priority for human resource managers, diversity and inclusion champions, change management consultants, leadership trainers, and corporate coaches. Academics, executive developers, educational leaders and administrators could benefit from this as well. These criteria could also be integrated into organizational performance management systems to ensure that those who are performing well in competencies linked to these intelligences, are rewarded for doing so.

\section{Conclusion and Directions for Future Research}

The conceptual bridge between multiple intelligences and change leadership presented in this paper has sought to provide human resource practitioners, change management consultants, researchers and educators with guidance regarding the emotional, executive, and cultural intelligence attributes predictive of effective change leadership. While the relationships between multiple intelligences and change leadership have been exploratory, it is hoped that the ideas offered will provide researchers with a framework upon which future theoretical and empirical work may be built. Future empirical research could, for example, test the relationships between Higgs and Rowland's (2000) change leadership competencies and multiple intelligences. Future research could also explore links between Higgs and Rowland's (2005 and 2011) change leader behaviors and executive, emotional and cultural intelligence. The relationship between change leadership "shaping" behavior and executive intelligence, for example, could be tested together with its impact on change resistance. Given that Avolio et al. (2009) called for more qualitative studies of leadership behaviors in multiple contexts and at multiple levels of analysis, future research could employ more large-scale collaborative qualitative techniques to explore these phenomena. The numerous interconnections between diverse types of intelligences and change leadership competencies could also be investigated using techniques like interviews and focus groups, to better explore these constructs at multiple levels of analysis (individual, group, and organizational) and in multiple cultural contexts (cross-culturally or between merging companies with diverse organizational cultures). This would further strengthen the theoretical and practical utility of emotional, executive and cultural intelligence in relation to change leadership. Ultimately, while technical change leadership competencies may suffice for change leaders managing minor incremental change, for effective transformational change to be achieved and sustained, high emotional, executive, and cultural intelligence are essential attributes of change leaders. Extraordinary change leaders ignite a passion and inspire the best in us, not just through technical expertise and innovative thinking strategies, but through emotions and things we value culturally.

\section{References}

Ang, S., \& Van Dyne, L. (2008). Conceptualization of cultural intelligence: Definition, distinctiveness, and nomological network. In S. Ang \& L. Van Dyne (Eds.), Handbook on cultural intelligence: Theory, measurement and applications, 3-15. Armonk, NY: M.E. Sharpe.

Avolio, B. J., Gardner, W. L., Walumba, F. O., Luthans, F., \& May, D. R. (2004). Unlocking the mask: A look at the process by which authentic leaders impact follower attitudes and behaviors. The Leadership Quarterly, 15, 801-823. https://doi.org/10.1016/j.leaqua.2004.09.003

Avolio, B. J., Walumba, F. O., \& Weber, T. J. (2009). Leadership: Current theories, research and future directions. Annual Review of Psychology, 60, 421-449. https://doi.org/10.1146/annurev.psych.60.110707.163621

Bass, B. M., \& Avolio, B. J. (1994). Improving organizational effectiveness through transformational leadership. Thousand Oaks, CA: Sage.

Beer, M. (2000). Research that will break the code of change: The role of useful normal science and usable action science, a commentary on Van de Ven and Argyris. In M. Beer \& Nohria (Eds.), Breaking the Code of Change, 429-447. Boston, MA: Harvard Business Press.

Bolman, L. G., \& Deal, T. E. (2011). Leading with Soul: An Uncommon Journey of Spirit. Jossey-Bass.

Boyatzis, R., \& McKee, A. (2005). Resonant Leadership. Boston, Massachusetts: Harvard Business School Press.

Collins, J. (2001). Good to Great: Why Some Companies Make the Leap and Others Don't. New York: Collins. 
Covey, S. R. (2004). The $8^{\text {th }}$ Habit: From Effectiveness to Greatness. New York: Free Press.

Earley, P. C., \& Ang, S. (2003). Cultural Intelligence: Individual interactions across cultures. Palo Alto, CA: Stanford University Press.

Earley P. C., \& Mosakowski, E. (2004). Cultural Intelligence. Harvard Business Review, 82(10), 139-146.

Gao-Urhahn, X., Biemann, T., \& Jaros, S. J. (2016). How effective commitment to the organization changes over time: A longitudinal analysis of the reciprocal relationships between affective organizational commitment and income. Journal of Organizational Behavior, 37, 515-536. https://doi.org/10.1002/job.2088

Gardner, H. (1983). Frames of Mind. New York: Basic Book Inc.

Gardner, H. (1993). Multiple Intelligences: The theory in practice. New York: Basic Books.

Gardner, W. L., \& Avolio, B. J. (2005). Authentic leadership development: Getting to the root of positive forms of leadership. The Leadership Quarterly, 16, 315-338. https://doi.org/10.1016/j.leaqua.2005.03.001

Goleman, D. (1995). Emotional Intelligence: Why it can matter more than IQ. New York: Bantam.

Goleman, D. (2004). What makes a leader? Harvard Business Review, 82, 82-91.

Goleman, D., Boyatzis, R. E., \& McKee, A. (2004). Primal leadership: Learning to lead with emotional intelligence. Boston: Harvard Business Press.

Higgs M., \& Rowland, D. (2000). Building change leadership capability: The quest for change competence. Journal of Change Management, 1, 116-130. https://doi.org/10.1080/714042459

Higgs M., \& Rowland, D. (2005). All changes great and small: exploring approaches to change and its leadership. Journal of Change Management, 5, 121-151. https://doi.org/10.1080/14697010500082902

Higgs M., \& Rowland, D. (2011). What does it take to implement change successfully? A study of behaviors of successful change leaders. The Journal of Applied Behavioral Science, 47(3), 309-335. https://doi.org/10.1177/0021886311404556

Hunter, J. E., \& Hunter, R. F. (1984). Validity and utility of alternate predictors of job performance. Psychological Bulletin, 96(1), 72-98. https://doi.org/10.1037/0033-2909.96.1.72

Hunter, J. E., \& Schmidt, F. L. (1990). Methods of meta-analysis. Newbury Park: Sage.

Ling, B., Guo, Y., \& Chen, D. (2018). Change leadership and employee's commitment to change: A multilevel motivation approach. Journal of Personnel Psychology, 17(2), 83-93. https://doi.org/10.1027/1866-5888/a000199

Lubeck, J., Cheng, B. S., Myszkowski, G., Doedijns, G., Drew, D., \& Snow, S. (2015). Future trends in business education. Hudson, OH: Executive Core, LLC.

Manning, T. T. (2003). Leadership across cultures: Attachment style influences. Journal of Leadership and Organizational Studies, 9, 20-32. https://doi.org/10.1177/107179190300900304

Menkes, J. (2005). Executive Intelligence: What All Great Leaders Have. HarperCollins Publishers, 259.

Menkes, J. (2005). Hiring for Smarts. Harvard Business Review, 82(11), 100-109.

Menkes, J. (2011). Hiring for Smarts. Harvard Business Review OnPoint, reprint.

Pettigrew, A. M., Woodman, R. W., \& Cameron, K. S. (2001). Studying organizational change and development: Challenges for future research. Academy of Management Journal, 44, 697-713.

Rockstuhl, T., \& Van Dyne, L. (2018). A bi-factor theory of the four-factor model of cultural intelligence: Meta-analysis and theoretical extensions. Organizational Behavior and Human Decision Processes, 148 , 124-144. https://doi.org/10.1016/j.obhdp.2018.07.005

Salovey, P., \& Mayer, J. D. (1990). Emotional intelligence. Imagination, Cognition, and Intelligence, 9, 185-211. https://doi.org/10.2190/DUGG-P24E-52WK-6CDG

Shokef, E., \& Erez, M. (2008). Cultural intelligence and global identity in multicultural teams. In S. Ang \& L. Van Dyne (Eds.), Handbook on cultural intelligence: Theory, measurement and applications, 177-191. Armonk, NY: M.E. Sharpe.

Tay, C., Westman, M., \& Chia, A. (2008). Antecedents and consequences of cultural intelligence among short-term business travelers. In S. Ang \& L. Van Dyne (Eds.), Handbook on cultural intelligence: Theory, measurement 
and applications, 126-144. Armonk, NY: M.E. Sharpe.

Van Dyne, L., \& Kim, Y. J. (2012). Cultural Intelligence and international Leadership Potential: The Importance of Contact for Members of the Majority. Applied Psychology: An International Review, 61(2), $272-294$. https://doi.org/10.1111/j.1464-0597.2011.00468.x

Van Dyne, L., Ang, S., Ng, K. Y., Rockstuhl, T., Tan, M. L., \& Koh, C. (2012). Sub-dimensions of the Four Factor Model of Cultural Intelligence: Expanding the Conceptualization and Measurement of Cultural Intelligence. Social and Personality Psychology Compass, 6, 295-313. https://doi.org/10.1111/j.1751-9004.2012.00429.x

Van Rooy, D. L., \& Viswesvaran, C. (2004). Emotional intelligence: A meta-analytic investigation of predictive validity and nomological net. Journal of Vocational Behavior, 65(1), $71-95$. https://doi.org/10.1016/S0001-8791(03)00076-9 